\title{
DOS POEMAS
}

(Diomedes. Arte gramatical. "Livro III"1)

\section{[Dos gêneros do poema]}

Os gêneros de poema são três. Com efeito, o gênero é ativo ou imitativo, que os gregos chamam dramatikón ou mimetikón; narrativo ou enunciativo, que os gregos chamam exegetikón ou apangeltikón; comum ou misto, que os gregos chamam koinón ou miktón. É dramatikón ou ativo aquele em que atuam somente as personagens, sem interlocução de algum poeta, como ocorre nas fábulas trágicas e cômicas, gênero no qual foi escrita a primeira Bucólica [de Vergílioº ] e aquela cujo início é "quo te, Moeri, pedes?"” ["Para onde, Meride, levam-te os pés?"]. É exegetikón ou narrativo aquele em que o próprio poeta fala, sem interlocução de alguma personagem, como ocorre nas três primeiras Geórgicas [de Vergílio] e na primeira parte da quarta, e igualmente nos cantos de Lucrécio ${ }^{4}$ e em outros semelhantes a estes. É koinón ou comum aquele em que o próprio poeta fala e as personagens são introduzidas falando, como foram escritas a Ilíada e a Odisséia inteiras, de Homero ${ }^{5}$, a Eneida, de Vergílio, e outros semelhantes a estes.

\section{Dos gêneros do poema dramatikós ou ativo}

Os gêneros do poema dramatikós ou ativo são quatro: entre os gregos, a [espécie] trágica, a cômica, a satírica, a mímica; entre os romanos, a pretextata, a tabernária, a atelana, a planípede.

\section{Da espécie do poema exegetikós ou narrativo}

As espécies do [poema] exegetikós ou narrativo são três: angeltiké [enunciativa], historiké [histórica], didaskaliké [didática]. É angeltiké aquela em que se es-

1 Seção do Livro III dos Artis grammaticae libri III. In: Grammatici latini. Ex recensione Henrici Keilii. Lipsiae: Teubner, 1855-74; págs. 482-492, edição a partir da qual foi realizada a presente tradução.

2 Públio Vergílio Marão, poeta latino, 70-19 a.C.

3 Vergílio, Bucólicas IX, 1.

4 Tito Lucrécio Caro, poeta latino, 97-55 a.C.

5 Homero, poeta grego, c. 730/20 a.C. 
crevem as máximas, como é o livro de Teógnide ${ }^{6}$, e igualmente khreía [crestomatia]. É historiké aquela em que se compõem narrativas e genealogias, como é o Gynaikôn katálogos [Catálogo das mulheres] de Hesíodo ${ }^{7}$ e semelhantes. É didaskaliké aquela em que se inclui a filosofia de Empédocles ${ }^{8}$ e de Lucrécio, e igualmente a astrologia, como os Fenômenos de Arato ${ }^{9}$ e de Cícero $^{10}$, as Geórgicas de Vergílio e semelhantes a estes.

\section{Da espécie do poema comum}

A primeira espécie do poema koinós ou comum é a heróica, como é a da Ilíada e a da Eneida; a segunda é a lírica, como é a de Arquíloco ${ }^{11}$ e a de Horácio ${ }^{12}$.

\section{[Dos caracteres do poema]}

Os caracteres do poema são quatro: makrós [longo], brakhýs [breve], mésos [médio], antherós [florido]. O caráter é makrós como em Vergílio, no ["Livro] XI" [da Eneida], onde este faz a narração sobre Camila assim: "[Metabo] foi expulso do reino por ódio e tirania sobre o povo"13; ou como ocorre nos "Livros II e III" [da Eneida]. O caráter é brakhýs como no ["Livro] V" [da Eneida], onde [Vergílio] narra sucintamente sobre Ganimedes assim:

"ao vencedor a clâmide dourada, em torno da qual, extensa, a Melibéia púrpura correu em duplo bordado, e nela o régio moço tecido, correndo o dardo, fatiga os cervos velozes no frondoso Ida" ${ }^{14}$.

6 Teógnide, poeta grego, séc. VI a.C..

7 Hesíodo, poeta grego, c. 710 a.C..

8 Empédocles, filósofo grego, c. 485 - c. 425 a.C..

9 Arato de Soles, poeta grego, c. 270 a.C..

10 Marco Túlio Cícero, orador latino, 106-43 a.C..

11 Arquílico de Paros, poeta grego, c. 680 - c. 630 a.C..

12 Quinto Horácio Flaco, poeta latino, 65-8 a.C..

13 Vergílio, Eneida XI, 539.

14 Vergílio, Eneida V, 250-253. 
É mésos como no ["Livro] I" [da Eneida]: "seu esposo era Siqueu, o mais rico em ouro/ entre os fenícios e, com grande amor, pela infeliz foi amado" ${ }^{15}$; com efeito, é narração trabalhada de tal modo que, contudo, abrace todas as coisas. É Antherós como no ["Livro] VII" [da Eneida], onde [Vergílio], descrevendo a amenidade do rio e do bosque, faz a narração assim:

"por entre este [bosque] o Tibre em corrente amena, com curvas rápidas e flavo pela muita areia, no mar irrompe; acima e em volta às margens, havia várias aves costumeiras que, pelo leito do rio, com o canto abrandavam os ares e no bosque voavam"16.

\section{[Dos cantos]}

Épos se diz em grego a inclusão das ações divinas, heróicas e humanas no canto hexâmetro, o qual foi definido pelos gregos deste modo: épos estìn periokhè theíon te kaì heroïkôn kaì anthropínon pragmáton ${ }^{17}$. Em latim, ouve-se dizer pouco mais comumente "canto". Primeiro escreveu dignamente o épos latino aquele que compreendeu as gestas dos romanos em dezoito livros, os quais ou se intitulam Anais, porque contêm acontecimentos quase ano a ano, assim como os anais públicos, que os pontífices e os escribas confeccionam, ou [se intitulam] [Livros] romanos porque declaram as gestas dos romanos. Chama-se épos, porém, como preceituam os gregos, parà tò hépesthai en autôi tà hexês mére toîs prótois. Na verdade, o verso hexâmetro se diz precipuamente épos, pois que por primeiro o deus vate incluiu neste verso as palavras da resposta, por assim dizer, em mútua consecução, de onde [vem] posteriormente, por catacrese, o termo; o épos por outros foi dita a palavra e a própria escrita consecutiva do discurso prosaico. Rapsódia se diz, em grego, poiéseos méros, certa parte discreta e isolada; deriva parà tò rháptein, porque os versos seriam cosidos e incluídos num único volume, ou porque, outrora, aqueles que a partir do próprio Homero se disseram homeristas, com um cajado, isto é, uma vara, pronunciavam parte do canto homérico nos círculos teatrais.

\footnotetext{
15 Vergílio, Eneida I, 343-344.

16 Vergílio, Eneida VII, 30-34.

17 Fragmento de Teofrasto, como muitos estudiosos sugerem (cf. FORTENBAUGH, W. W. et alii. Theophrastus of Eresus. Brill, 1993)
} 
Elegia é o canto composto em verso hexâmetro e pentâmetro, dispostos alternadamente como: "outro para si acumule a riqueza em ouro fulvo/ e mantenha do cultivado solo muitas geiras" ${ }^{18}$; gênero de canto que, entre os romanos, escreveram principalmente Propércio ${ }^{19}$, Tibulo ${ }^{20}$ e Galo ${ }^{21}$, que imitaram os gregos Calímaco $^{22}$ e Euforião ${ }^{23}$. A elegia, por sua vez, disse-se quer parà to eû légein toùs tethneôtas (pois quase todos os elogios aos mortos eram compreendidos neste canto), quer apò toû eléou, isto é, comiseração, porque os gregos tinham o hábito de escrever neste metro thrénous ou eleê̂a. Com esta opinião parece consentir Horácio, quando, ao escrever a Álbio Tibulo, autor de elegias, por causa daquela comiseração que dissemos, diz míseras as elegias, deste modo: "não cantes/ elegias míseras"24. Entre os romanos, por sua vez, aquele canto que, extremo e último, ao morto se canta com lamento, diz-se nênia parà tò neíaton, isto é, éskhaton; de onde também nas cordas o último nervo foi chamado néte. E, com efeito, a elegia extrema cantava-se ao morto, assim como a nênia e, por isso, a elegia parece ser denominada segmento que por último se escreve aos que morreram ou aos que estão por morrer.

O iambo é um canto de maldizer, quase sempre composto em verso trímetro seguido de epodo, como: "aberta a vela, em mau auspício parte a nau/ que leva o fedorento Mévio"25; [canto] que foi chamado por sua vez parà tò iambízein, que significa maldizer. Os principais escritores desse canto são, entre os gregos, Arquíloco e Hiponacte ${ }^{26}$; entre os romanos, Lucílio ${ }^{27}$, Catulo ${ }^{28}$, Horácio e Bibáculo ${ }^{29}$.

18 Tibulo, Livro de elegias I, 1, 1-2; aqui, minha tradução não recupera o verso hexâmetro seguido de pentâmetro como está no original em latim exemplificando a definição de elegia.

19 Sexto Propércio, poeta latino, c. 54 - c. 19/18 a.C.

20 Álbio Tibulo, poeta latino, c. 48 "19 a.C.

21 Cornélio Galo, poeta latino, 69-26 a.C.

22 Calímaco, poeta grego, séc. III a. C..

23 Euforião, poeta grego, séc. III a.C..

24 Horácio, Odes I, 33, 2-3.

25 Horácio, Epodos 10, 1-2.

26 Hiponacte, poeta grego, c. 540 a.C.

27 Caio Lucílio, poeta latino, 168/167 - 103/102 a.C..

28 Caio Valéro Catulo, poeta latino, c. 87-54 a.C.

29 Fúrio Bibáculo, poeta latino, 103-? a.C. 
Epodos dizem-se os versos escritos em qualquer metro e seguidos de cláusulas de pequenas partes [de verso], tais quais são os epodos de Horácio, em que a cada verso uma cláusula é adicionada, como: "era noite e fulgia a lua no céu sereno"30, em seguida, "entre os astros menores"31; e, "outra geração já é destruída pelas guerras civis" ${ }^{32}$, depois, "e pela suas forças rui a própria Roma" ${ }^{33}$; e quaisquer que sejam semelhantes. Os epodos, porém, são ditos synekdokhikôs, por causa das partes de versos, que com legítimos e íntegros versos epádontai, isto é, são acompanhadas pelo canto.

Sátira diz-se o canto que, agora sim, entre os romanos é maledicente e composto no gênero da antiga comédia, para censurar os vícios dos homens, tal qual escreveram Lucílio, Horácio e Pérsio ${ }^{34}$. Ainda, outrora, o canto que constava de vários poemas era denominado sátira, tal qual escreveram Pacúvio ${ }^{35}$ e Enio $^{36}$. Sátira, porém, diz-se quer pelos sátiros, porque semelhantemente neste canto são ditas coisas risíveis e pudendas, como as que pelos sátiros são proferidas e realizadas; quer sátura, diz-se, pelo prato que, cheio de várias e muitas primícias, oferecia-se aos deuses no sacramento, e, pela abundância e saturação da colheita, era denominado sátura " também Vergílio lembrou-se desse gênero de pratos nas Geórgicas, quando disse deste modo: "em pratos densos oferecemos as vísceras fumegantes" ${ }^{37}$ e "oferecemos pratos e bolos" 38 "; quer por certo gênero de salsicha que, recheada com muitas coisas, Varrão ${ }^{39}$ diz ter sido costume denominar-se sátura. Ora, isso está dito no "Livro II" das Questões plautinas: "sátura é uva-passa, farinha de polenta e miolos de pinho banhados em vinho melado"40; a estas coisas outros adicionam também grãos de romã. Outros, porém, pensam ter sido dita a partir da Lei Sátura, a qual, com uma única solicitação compreenderia simultaneamente

\footnotetext{
30 Horácio, Epodos 15, 1.

31 Horácio, Epodos 15, 2.

32 Horácio, Epodos 16, 1.

33 Horácio, Epodos 16, 2.

34 Pérsio Flaco, poeta latino, 34-62 d.C..

35 Pacúvio, poeta latino, 220 - c. 130 a.C..

36 Quinto Ênio, poeta latino, 239-169 a.C..

37 Vergílio, Geórgicas II, 194.

38 Vergílio, Geórgicas II, 394.

39 M. Terêncio Varrão, 116-27 a.C..

40 Livro hoje perdido.
} 
muitas coisas, porque, bem entendido, também no canto sátura simultaneamente muitos poemas são compreendidos. Desta Lei Sátura Lucílio se lembra no ["Livro] I": "o qual dispense um edil eleito [de obedecer] às leis por meio da [Lei] Sátura" também Salústio ${ }^{42}$, na Guerra de Jugurta: "e mais, como que por meio da [Lei] Sátura, com sentenças apuradas aceitou-se a rendição"

Bucólicos são ditos os cantos compostos segundo o canto pastoril. Assim como alguns pensam, foram instituídos na Lacônia ou, como outros, na Sicília; com efeito, foi de diversa origem entre os lacedemônios e sículos. Mas, no que diz respeito aos lacones, sua origem foi a seguinte: no tempo em que Xerxes invadiu a Grécia, crê-se que todos, atemorizados, tenham fugido para diversas regiões, abandonando a Lacônia por medo dos bárbaros, e que, como as moças por causa do temor se escondessem, daí sucedeu que, naquele dia em que o coro das virgens costumava cantar o hino à Diana Cariátide, não se encontrasse ninguém para [cantar] o sacrifício solene. E assim, então, os pastores vieram do campo para a cidade e, para que o rito dos sacramentos não fosse interrompido, celebraram a honra da deusa com a composição de um canto pastoril, de onde foi dito "bucolismo". Dos sículos, por sua vez, a origem que se transmite é esta: antes que o rei Hierão tomasse Siracusa, a Sicília sofria com uma moléstia; aplacando Diana com várias e assíduas cerimônias, [os sículos] encontraram o fim para os males e apelidaram-na Liéia, isto é, solucionadora dos males. Daí o caso foi transmitido ao costume, de maneira que as greis de camponeses entrassem no teatro e cantassem a vitória. Por outro lado, parecia ser um costume, assim: havia um grande pão recheado com a imagem de todas as feras, e um odre, com vinho e, ainda, uma bolsa [recheada] com todo gênero de legumes; também havia tanto uma coroa sobre a cabeça quanto um cajado cravejado na mão; desse modo, a multidão de todos os vitoriosos circundava as portas, cantava o canto pela vitória adquirida e daquela bolsa espalhavam frutos na soleira da porta. Acredita-se que não poucos atravessaram tanto para a Itália como para a Lídia e para o Egito, aos quais chamaram lidiastas e bucolistas. Todavia, também existe outra opinião: que, em volta dos povoados e cidades, os pastores costumavam suplicar pelo provento dos gados, dos frutos e dos homens com a composição de um canto e, daí, até hoje permanecerem o nome e o rito dos bucólicos. Pensam alguns, porém, que primeiro Dafne compôs

\footnotetext{
41 Livro hoje perdido.

42 Caio Salústio Crispo, historiógrafo e político latino, 86-34 a.C..

43 Salústio, Guerra de Jugurta 29, 5, 4.
} 
tal gênero de canto e, depois, outros mais, entre os quais, Teócrito de Siracusa ${ }^{44}$ o qual o nosso [Vergílio] imita.

A tragédia é a inclusão da fortuna heróica na adversidade. Por Teofrasto ${ }^{45}$ foi assim definida: tragoidía estìn heroïkés týkhes perístasis. A tragédia, como alguns [pensam], foi dita a partir de trágos e de aoidé, pois que outrora o trágos, isto é, o bode, era proposto aos atores trágicos como prêmio do canto, o qual era imolado nas Liberais, em dia festivo ao pai Líbero, pelo seguinte, porque, como diz Varrão: "consomem a videira"; e Horácio, na Arte poética: "aquele que com o poema trágico disputou por um bode vil/ logo também despiu os sátiros agrestes" ${ }^{\text {46 }}$; e Vergílio, no ["Livro] II" das Geórgicas, quando demonstra o gênero de [canto] sagrado e a causa de tal vítima, exprime com estes versos: "não por outra causa, o bode em todos os altares era, a Baco,/ sacrificado"47. Outros, porém, pensam que [a partir] de borra, que alguns dos gregos chamam trýx, denominou-se a tragédia, por mudança da letra $y$ em $a$, pois que outrora, quando as personagens ainda não tinham sido inventadas por Téspis, atuavam semelhantes fábulas com as faces untadas com borra, como disso mais uma vez Horácio é testemunha, assim: "diz-se ter inventado o gênero da Camena trágica/ Téspis, e levado nos carros os poemas,/ os quais os atores cantassem e atuassem com as faces toda untadas" ${ }^{\prime 48}$. Outros julgam que de vinho [se denominou a tragédia], em conseqüência de outrora costumar-se chamar trýx, de que vem trýgetos e, hoje, vindima, porque nas Liberais, no dia festivo ao pai Líbero, entre os áticos, o vinho era dado aos cantores em lugar de coroazinhas, caso de que Lucílio é testemunha no "Livro XII"49.

A comédia é a inclusão de acontecimentos privados e civis sem perigo de vida, definida entre os gregos desse modo: komoidía estìn idiotikôn pragmáton akíndynos periokhé $e^{50}$. A comédia foi dita apò tôn komôn; com efeito, os povoados são chamados kómai, isto é, ajuntamentos de camponeses. E assim a juventude ática, como disse Varrão, fora habituada a andar nas imediações das aldeias e, para obter algum dinheiro, pronunciava este gênero de canto. Ou decerto [comédia foi dita] a partir dos jogos

\footnotetext{
44 Teócrito de Siracusa, poeta grego, séc. III a.C..

45 Teofrasto, filósofo grego, 371-287 a.C..

46 Horácio, Arte poética 220-221.

47 Vergílio, Geórgicas II, 380-381.

48 Horácio, Arte poética 275-277.

49 Livro hoje perdido.

50 Fragmento de Teofrasto, como muitos estudiosos sugerem.
} 
vicinais; com efeito, depois que migraram dos campos para Atenas, e estes jogos foram instituídos, assim como as compitais em Roma, apresentavam-se para cantar, e da urbana kóme e oidé foi chamada comédia; ou porque nela os acontecimentos das aldeias eram inclusos, isto é, [os] das habitações humildes, não como na tragédia [os acontecimentos] das casas públicas e reais; ou apò tô̂ kómou, isto é, de comezaina, porque, outrora, nessas fábulas cantavam-se os kômoi dos jovens amantes.

A comédia difere da tragédia porque na tragédia são introduzidos heróis, chefes, reis; na comédia, personagens rasteiras e privadas; naquela, lutos, exílios e assassinatos, nesta, amores e raptos de moças; depois, porque naquela, freqüentemente e quase sempre, por coisas ledas, finais tristes e reconhecimento de filhos e fortunas $\langle\ldots\rangle^{51}$. Por isso elas foram distinguidas com definição vária: uma, com efeito, akíndynos periokhé, outra týkhes perístasis foi dita, porque a tristeza é o próprio da tragédia. E por isso Eurípides ${ }^{52}$, ao lhe pedir o rei Arquelau que de si escrevesse uma tragédia, negou e suplicou que não acontecesse a Arquelau algo próprio da tragédia, mostrando que a tragédia nada mais é que a inclusão de misérias.

Os primeiros poetas cômicos foram Susarião Mulo ${ }^{53}$ e Magnete $^{54}$. Estes enunciavam menos apurada e elegantemente certas jocosidades da antiga educação, como estes versos: sousaríon taûta légei/ kakòn gynaikes all'hómos, ô demótai,/ ouk éstin eyreîn oikían áneu kakoû ["diz Susarião isto: as mulheres são um mal, mas, no entanto, ó concidadãos, não há como encontrar um lar sem mal]. Na segunda geração foram Aristófanes ${ }^{55}$, Eupólide ${ }^{56}$ e Cratino ${ }^{57}$ [os poetas], os quais, por terem seguido os vícios dos primeiros, compuseram as mais acerbas comédias. A terceira geração foi de Menandro ${ }^{58}$, Dífilo ${ }^{59}$ e Filemão ${ }^{60}$, os quais atenuaram toda a

51 Na lacuna, Diomedes talvez tivesse indicado o final típico para a comédia, o final feliz, em oposição ao da tragédia, para seguirmos a explicação por oposição dos dois gêneros dramáticos.

52 Eurípedes, poeta grego, 480-406 a.C..

53 Susarião Mulo, poeta grego, séc. VI a.C..

54 Magnete, poeta grego, séc. V a.C..

55 Aristófanes, poeta grego, c. 447 - c. 386 a.C..

56 Eupólide, poeta grego, séc. V a.C..

57 Cratino, poeta grego, séc. V a.C..

58 Menandro, poeta grego, séc. IV-III a.C..

59 Dífilo, poeta grego, séc. IV-III a.C..

60 Filemão, poeta grego, 361-262 a. C. 
acerbidade da comédia e buscaram assuntos múltiplos para as incorreções gregas. Destes os romanos traduziram as fábulas, e consta que, entre estes, primeiro escreveu comédia em língua latina Lívio Andronico ${ }^{61}$. Há aqueles que queiram que Epicarmo $^{62}$, que fora exilado na ilha de Cós, primeiro tenha freqüentado tal canto, e que, assim, de "Cós" é dita a comédia. Antes, usavam de gáleas, não de máscaras, de modo que a propriedade da cor indicasse a idade, conforme fossem ou brancas, ou negras, ou vermelhas ${ }^{63}$. Primeiro começou a usar das máscaras Róscio Galo, precípuo histrião, porque possuía olhos tortos e não pronunciava suficientemente decoroso os papéis a não ser como parasito.

No início as comédias diziam-se togatas, porque todas as coisas se discerniam mescladas nas honras públicas. Tais togatas depois foram divididas em pretextatas e tabernárias. Dizem-se fábulas togatas aquelas que foram escritas segundo os ritos e o hábito dos homens togados, isto é, dos romanos (pois que a toga é romana), assim como as fábulas gregas afirma Varrão serem igualmente nomeadas paliatas pelo hábito. Porém, embora seja nome geral, especificamente, em lugar de tabernárias, usurpa de togatas não só o erro comum, que chama togatas [as comédias] de Afrânio ${ }^{64}$, mas também os poetas, como Horácio que diz: "os que pretextatas ou os que togatas compuseram". As espécies de fábulas togatas são quase tantas quantas as de paliatas; pois a primeira é a espécie de togatas que são chamadas pretextatas, nas quais os negócios e [afazeres] públicos dos imperadores são atuados, e os reis e chefes romanos são introduzidos, semelhantes às tragédias, pela dignidade e sublimidade das personagens. São ditas pretextatas, porém, porque em fábulas desse tipo são compreendidos os atos dos reis e dos magistrados que usam da pretexta. A segunda é a espécie de togatas que são chamadas tabernárias, e pela humildade das personagens e similitude dos assuntos são pares das comédias, nas quais são introduzidos não magistrados ou reis, mas homens humildes e casas parti-

61 Lívio Andronico, poeta latino, c. 284 - c. 204 a.C..

62 Epicarmo, poeta latino, 530-440 a.C..

63 Trecho obscuro, pois que não nos é explícito o que tais cores adjetivam; poderíamos inferir que as cores indicam a idade ou a condição civil das personagens, não tanto a partir do texto de Diomedes, mas dos comentários Aulo-Gélio, que apontam que o velho geralmente apareceria em cena de cabelos brancos, o jovem, de cabelos negros, os escravos, de cabelos vermelhos (cf. BEARE, William. The Roman stage: a short history of Latin drama in the time of the Republic. London: Methuen, [1964], p. 178).

64 Lúcio Afrânio, poeta latino, n. c. 150 a.C.., de cujas comédias nos chegaram apenas fragmentos. 
culares, as quais, decerto porque, outrora, fossem cobertas por mesas, eram comumente chamadas tabernas. A terceira é a espécie das fábulas latinas que, pela cidade Atela dos oscos, na qual foi primeiro empreendida, foram chamadas atelanas, semelhantes às fabulas satíricas gregas pelos assuntos e ditos jocosos. A quarta é a espécie planípede, que em grego se diz mimo. Em latim, por sua vez, diz-se planipes [planípede] por isto: os atores entrariam no proscênio com pés no chão, isto é, nus, não como os atores trágicos com coturnos nem como os cômi$\cos \operatorname{com} \operatorname{socos}^{65}$; ou porque outrora estavam postos os instrumentos mímicos não na elevação da cena, mas no plano da orquestra. De tal planípede, Ata ${ }^{66}$, escritor de togatas, assim se lembrou na fábula Edilícia: "ireis dar o ouro? " exulta o planípede”. Todavia, algumas fábulas fossem representadas com socos, os paliatos enunciavam.

A togata pretextata difere da tragédia porque na tragédia introduzem-se heróis, como Pacúvio escreveu tragédias com nomes de heróis, Orestes, Crises e semelhantes a estes, e igualmente Ácio ${ }^{67} \mathrm{o}$ fez na pretextata, que foram intituladas Bruto, Décio e, igualmente, Marcelo. A togata tabernária difere da comédia porque, na comédia, introduzem-se ritos gregos e personagens gregas: Laquete, Sóstrata; naquela, porém, [personagens] latinas. Deram amiúde as togatas tabernárias no teatro precipuamente dois, L. Afrânio e G. Quíncio ${ }^{68}$, pois que Terêncio ${ }^{69}$ e Cecílio ${ }^{70}$ escreveram comédias. A atelana latina difere da satírica grega porque, na satírica, introduzem-se quase sempre personagens dos sátiros, ou algumas que sejam ridículas semelhantes aos sátiros: Autólico, Busíris; na atelana, personagens oscas, como Maco.

Os dramas, por sua vez, trágicos ou cômicos, são ditos parà tò drân, isto é, atuar. Em latim são chamados fabulae [fábulas] ou fatibulae [fatíbulas] " com efeito, nas fábulas latinas muitos são os cânticos que são cantados " talvez a partir de "fazer" " com efeito, diz-se que a fábula é atuada, não referida pelos atores. E por

65 Socos, calçados usados pelos atores na comédia, que, por metonímia, identificam tal gênero, assim como os coturnos, a tragédia.

T. Quíncio Ata, poeta latino, m. 77 a.C..

67 Ácio, poeta latino, c. 170-86 a.C..

68 G. Quíncio, aparentemente obscuro, embora, a partir de notícias sobre os que escreveram togatas, poderia inferir que é o mesmo T. Quíncio Ata supracitado.

69 Terêncio Africano, poeta, c. 190 - c. 159 a.C..

70 Cecílio Estácio, poeta latino, m. 168 a.C.. 
isso Horácio com ambos os sentidos explica, quando assim fala sobre a fábula: "a ação é atuada na cena ou é referida", assim como no coro. No drama grego aproximadamente só três personagens atuam e, por isso, Horácio disse: "nem uma quarta personagem se esforce para falar", porque a quarta é sempre muda. Os escritores latinos, porém, introduziram bem mais personagens nas fábulas, para que com a abundância as fizessem mais especiosas.

A satírica é, entre os gregos, a fábula na qual do mesmo modo os poetas trágicos introduziram não heróis ou reis, mas sátiros, por motivo de brincadeira e jocosidade, para que, ao mesmo tempo, o espectador, entre casos trágicos e sérios, se deleitasse com os jogos e as brincadeiras dos sátiros, como Horácio percebeu nestes versos:

"aquele que disputou com um canto trágico por um bode vil, logo também despiu os agrestes sátiros e, áspero, ficando a gravidade incólume, tentou o risível, por isso deveria ser atraído pelos atrativos e pela grata novidade o espectador $[\ldots] "$

O mimo é a imitação de qualquer discurso e movimento sem reverência, ou imitação de feitos e ditos torpes, com lascívia. Pelos gregos, assim foi definido: mîmós estin mímesis bíou tá te sygkekhoreména kaì asygkhóreta periékhon. O mimo foi chamado parà tò mimeîsthai, como se só ele imitasse, embora outros poemas o mesmo façam; mas, como que por certo privilégio, possuiu sozinho o que foi comum. Semelhantemente aquele que faz o verso foi chamado poietés, embora os artífices, conquanto igualmente façam algo, não sejam chamados poetas.

As partes das comédias são três: diálogo, cântico e coro. As partes da comédia são diversas; todavia, definido o número, são contidas entre cinco e dez [partes]. Os diálogos são as partes da comédia nas quais as personagens conversam sobre casos diversos. As personagens dos diálogos, por sua vez, ou devem ser duas ou três, ou raramente quatro; para além deste número não convém aumentar. Nos cânticos, por sua vez, somente uma deve ser a personagem, ou, se forem duas, de tal modo devem ser que, de trás da cortina, uma única ouça e não converse, mas consigo, se tiver sido o caso, diga as palavras. Nos coros, o número de personagens não foi, na verdade, definido, pois que todas devem juntamente falar, como que formando uma única personagem, com voz mesclada e com consonância. Logo, as comédias latinas não possuem coro, mas constam de tão-somente duas partes, o diálogo e o cântico. Nos primeiros tempos, entretanto, assim como afirma Tran- 
qüilo $^{71}$, na comédia se atuava tudo o que na cena era conversado; com efeito, tocavam na comédia tanto o pantomimo como os pitaules e coraules ${ }^{72}$. Mas, porque nem tudo podia, a um tempo só, ser igualmente excelente em todos os artífices, se alguns entre os atores de comédias eram preferíveis pela faculdade e arte, reivindicavam para si a primazia do artifício. Assim, sucedeu que para os mimos que não queriam ceder para outros no seu artifício, se fizesse separação dos restantes; com efeito, enquanto os preferíveis desdenhavam servir os inferiores, os quais estavam em oficina comum, separaram-se da comédia, e assim sucedeu que cada um, após usar do exemplo uma vez tomado, começasse a buscar o caso de sua arte, e a não ir à comédia. Indícios deste caso mostram-nos as antigas comédias, nas quais encontramos [o verso]: "executados por flautas pares ou ímpares ou sarranas"; com efeito, quando o coro cantava, o artífice juntamente cantava com as flautas corais, isto é, coráulicas; no cântico, porém, respondia com [as] pitáulicas. Mas, porque encontramos a escrita para 'flautas pares' ou 'ímpares', isto significa que, quando o monódico atuava, uma única flauta soava; quando o sinódico, várias.

Tradução de IZABELLA LOMBARDI GARBELLINI PPG Letras Clássicas FFLCH/USP

\section{INFORME}

Esta tradução é parte de um projeto de Iniciação Cientifica intitulado "Tradução e comentários do De poematibus de Diomedes". O projeto foi desenvolvido no PPG Letras Clássicas da FFLCH/USP, sob a orientação do Prof. Dr. Marcos Martinho dos Santos, ao longo do $2^{\circ}$ semestre de 2004 e $1^{\circ}$ semestre de 2005, com bolsa PIBIC do CNPq, e os resultados foram apresentados no 13은 SIICUSP realizado nos dias 7, 8 e 9 de novembro de 2005. Recebeu menção honrosa da Comissão Organizadora do 13o SIICUSP. Em 24 de abril de 2006, foi selecionado, dentre os

71 Tranqüilo, sobrenome romano comum; talvez, Suetônio Tranqüilo, historiador latino, c. $70-122$ d.C..

72 Pitaules e coraules são tocadores de flauta [aulós], como o nome indica. 
que receberam menção honrosa, para receber o prêmio da Pró-Reitoria de Pesquisa da USP. Com o prêmio da Pró-Reitoria de Pesquisa da USP, a orientanda desenvolveu as seguintes atividades na Inglaterra: (a) de 1 a 6 de setembro de 2006: pesquisa bibliográfica, na Bodleian Library e na Sackler Library da Oxford University (Oxford, Reino Unido); (b) de 7 a 9 de setembro de 2006: apresentação da comunicação "The De poematibus by Diomedes" em "The 2006 colloquium of the Henry Sweet". 